\title{
THE MARCH MEETING IN LOS ANGELES
}

The six hundred fifty-fourth meeting of the American Mathematical Society was held at the University of California, Los Angeles on Thursday, Friday and Saturday, March 21-23, 1968. There were 223 registrants, including 112 members of the Society.

By invitation of the Committee to Select Hour Speakers for Far Western Sectional Meetings, Professor Rimhak Ree of the University of British Columbia presented an hour address on Characters of finite Chevalley groups. He was introduced by Professor L. J. Paige.

There were six sessions for contributed papers, chaired by Professors J. D. Brillhart, A. H. Cayford, J. E. Kohler, N. S. Mendelsohn, J. L. Selfridge, T. H. Southard, and G. K. White.

By invitation of the Committee to Select Hour Speakers for Far Western Sectional Meetings, and with the financial support of the National Science Foundation, a Symposium on Combinatorics was held on Thursday and Friday, March 21-22. The Organizing Committee for the symposium consisted of Professors T. S. Motzkin (chairman), Marshall Hall, and Gian-Carlo Rota. The speakers and titles of their addresses were as follows: Professor Basil Gordon, University of California, Los Angeles, Plane partitions; Professor M. S. Cheema, University of Arizona, Multipartitions and multipermutations; Dr. Oliver Atkin, Atlas Computer Laboratory, Didcot, Berkshire, England, and Professor H. P. F. Swinnerton-Dyer, University of Cambridge, Combinatorics applied in number theory; Professor W. T. Tutte, University of Waterloo, Dichromatic sums for planar maps; Professor V. L. Klee, University of Washington, Some combinatorial problems connected with convex polytopes; Professor Richard Rado, University of Reading, Berkshire, England, Some problems in the partition calculus; Professor T. S. Motzkin, University of California, Los Angeles, Classification numbers and their generalizations; Dr. Bruce Rothschild, Massachusetts Institute of Technology, Generalizations of Ramsey's Theorem; Professor Paul Erdös, Hungarian Academy of Sciences, Problems and results in combinatorial analysis; Professor D. J. Kleitman, Massachusetts Institute of Technology, Families of subsets of a finite set containing no two subsets and their union; Professor A. W. Hales, University of California, Los Angeles, Combinatorial representations of abelian groups; Dr. Alexander Hurwitz, I. B. M., Los Angeles, Homogeneous 0-1 matrices; Professor 
D. K. Ray-Chaudhuri and Mr. R. M. Wilson, Ohio State University, On Kirkman designs; Dr. Olga Taussky, California Institute of Technology, $(2,4,8)$-sums of squares and Hadamard matrices; Professor Marshall Hall, Jr., California Institute of Technology, Groups and combinatorial designs; Professor J. D. Swift, University of California, Los Angeles, On $(k, l)$-coverings and disjoint sets; Professor E. G. Straus, University of California, Los Angeles, Non-averaging sets of integers; Professor Paul Erdös, Hungarian Academy of Sciences, and Professor Leo Moser, University of Alberta, and University of California, Santa Barbara, On the number of scores of tournaments; Professor N. S. Mendelsohn, University of Manitoba, A combinatorial method for embedding a group in a semigroup; Professor E. T. Parker, University of Illinois, Some pathological latin squares; Professor Raj C. Bose, University of North Carolina, Self-conjugate tetrahedra with respect to the hermitian variety $x_{0}{ }^{3}+x_{1}{ }^{3}+x_{2}{ }^{3}+x_{3}{ }^{3}=0$ in $P G\left(3,2^{2}\right)$, and a representation of $P G(3,3)$; Professor Haim Hanani, Israel Institute of Technology and City University of New York, Truncated finite planes; Professor H. H. Crapo, University of Waterloo, and Professor Gian-Carlo Rota, Massachusetts Institute of Technology, Truncated finite planes. The presiding officers at the six sessions of the symposium were Professors George Pólya, Marshall Hall, Jr., T. S. Motzkin, H. B. Mann, E. F. Beckenbach, and H. J. Ryser.

There was a party on Friday evening in the Recreation Center on the UCLA campus for members of the Society and their guests.

R. S. PIERCE

Associate Secretary

Las Cruces, New Mexico 